\title{
O CONCEITO DE ECOSSISTEMA EM LIVROS DIDÁTICOS DE BIOLOGIA DO ENSINO MÉDIO: ABORDAGEM E POSSÍVEIS IMPLICAÇÕES
}

\author{
RODOLFO ZAMPIERI BEZZON ${ }^{1}$ \\ ORCID: https://orcid.org/0000-0002-1057-5559 \\ RENATO EUGÊNIO DA SILVA DINIZ² \\ ORCID: https://orcid.org/0000-0002-0192-3988
}

\begin{abstract}
RESUMO: Pesquisas apontam que o livro didático possui papel singular nos ambientes escolares, principalmente após a criação do Programa Nacional do Livro Didático (PNLD). Os objetivos deste estudo são identificar e analisar como o conceito de ecossistema é abordado em algumas coleções didáticas de Biologia selecionadas pelo PNLD/2015. Investigar como o conceito de ecossistema é abordado em livros didáticos é importante para o ensino-aprendizagem em Ecologia, porque esse conceito fomenta grande parte das discussões em políticas ambientais e pesquisas em Biologia. Além disso, o livro didático pode ter importante papel na estruturação das aulas e está sujeito a conflitos de interesse. Neste estudo, foram analisadas três coleções didáticas por meio da Análise de Conteúdo, de Bardin (2011), com interpretação de como os conteúdos presentes nas coleções abordam e direcionam a significação do conceito de ecossistema. Os resultados demonstram um padrão na abordagem desse conceito, em todas as coleções, que simplifica, não historiza e, muito menos, critica o conceito de ecossistema.
\end{abstract}

Palavras-chave: Conceito de Ecossistema, Livro Didático, Ensino de Ecologia, Análise de Conteúdo.

\section{THE ECOSYSTEM CONCEPT IN HIGH SCHOOL BIOLOGY TEXTBOOKS: APPROACH AND POSSIBLE IMPLICATIONS}

\begin{abstract}
Researches suggest that the textbook has a major role at scholar environments, especially after the creation of the Textbook National Program (TNP). The objectives of this study were to identify and analyze how the ecosystem concept is approached in the collections of Biology textbooks selected from the TNP/2015. Investigating how the ecosystem concept is presented in textbooks is important for the teaching-learning process in Ecology, because this concept foments great part of the environmental politics discussions and the researches in Biology. Besides, the textbook can be used as a guide to structure classes and it is subject to conflicts of interest. In this study, three didactic collections were analyzed using Bardin's (2011) Content Analysis, with interpretation of how the contents present in the collections of textbooks approach and direct the signification of the ecosystem concept. The results demonstrate a pattern on the approach through all collections that simplifies, do not historicize and neither criticize the ecosystem concept.
\end{abstract}

\footnotetext{
1 Universidade de São Paulo - Faculdade de Educação. São Paulo, SP, Brasil. <bezzonrodolfo@gmail.com>.

${ }^{2}$ Universidade Estadual Paulista "Júlio de Mesquita Filho" - Instituto de Biociências. Botucatu, SP, Brasil. <renato.es.diniz@unesp.br>.
} 
Keywords: Ecosystem Concept, Textbook, Ecology Teaching, Content Analysis.

\section{EL CONCEPTO DE ECOSISTEMA EN LIBROS DE TEXTO DE BIOLOGÍA DE LA ESCUELA SECUNDARIA: ENFOQUE E POSIBLES IMPLICACIONES}

RESÚMEN: Las investigaciones sugieren que el libro de texto tiene un papel importante en los entornos académicos, especialmente después de la creación del Programa Nacional de Libros de Texto (PNLT). Los objetivos de este estudio fueron identificar y analizar cómo se aborda el concepto de ecosistema en las colecciones de libros de texto de Biología seleccionados del PNLT/2015. Investigar cómo se presenta el concepto de ecosistema en los libros de texto es importante para el proceso de enseñanza-aprendizaje en Ecología, porque esto concepto fomenta gran parte de las discusiones de política ambiental y las investigaciones en biología. Además, el libro de texto puede usarse como una guía para estructurar clases y está sujeto a conflictos de intereses. En este estudio, se analizaron tres colecciones didácticas utilizando el Análisis de Contenido de Bardin (2011), con la interpretación de cómo los contenidos presentes en las colecciones de libros de texto se acercan y dirigen la significación del concepto de ecosistema. Los resultados demuestran un patrón en el enfoque a través de todas las colecciones que simplifica, no historiza y tampoco critica el concepto de ecosistema.

Palabras clave: Concepto de Ecossistema, Libros de Texto, Enseñanza de Ecología, Análisis de Contenido. 


\section{INTRODUÇÃO}

O conceito de ecossistema é elemento chave para a estrutura do conhecimento da Ecologia e, por tal motivo, deve ser profundamente compreendido em toda sua complexidade (WILLIS, 1997; PICKETT; CADENASSO, 2002; ODUM, 2007; KATO, 2014). Isso significa que o contexto históricosocial de sua elaboração, as influências que sofreu ao longo do tempo e sua importância para o conhecimento ecológico, para a própria Ciência e para a sociedade, devem ser compreendidos (FRACALANZA, D. C., 1992; SATO; CARVALHO, 2005; SENICIATO; CAVASSAN, 2009; KATO; KAWASAKI; CARVALHO, 2020). Por isso, no presente estudo, decidiu-se por fazer um recorte, focalizando a abordagem desse conceito em livros didáticos de Biologia para o Ensino Médio. O foco no livro didático foi escolhido por se considerar que uma análise dos conteúdos presentes nele é relevante, visto que ele orienta, de forma expressiva, a prática docente, e também porque se torna possível identificar as potencialidades e limites desse material, possibilitando ao professor maior percepção e aperfeiçoamento de sua práxis (MEGID NETO; FRACALANZA, 2003; NOSELLA, 2005; MARTINS; GOUVÊA; VILANOVA, 2012).

\section{O LIVRO DIDÁTICO}

Alguns trabalhos apontam que o livro didático possui um papel de destaque no ambiente escolar, principalmente após a criação do Programa Nacional do Livro Didático (PNLD) pelo Ministério da Educação (MEC) (FRACALANZA, H., 1992; HÖFLING, 2000; VASCONCELOS; SOUTO, 2003; BITTENCOURT, 2004; CASSIANO, 2007). Segundo tais pesquisas, esse é um dos materiais mais utilizados por professores, para as seguintes atividades: estruturação e desenvolvimento de planos de aula; checagem e atualização de conteúdos; aplicação e resolução de exercícios; apoio durante as aulas com esquemas, fotos, gráficos e textos; dentre outras. Justamente por ter tamanha relevância dentro das escolas e na práxis docente, os livros didáticos têm sido investigados em suas diferentes facetas, sendo problematizados desde sua definição, elaboração e produção, passando pela sua utilização em salas de aula, tanto por professores quanto por alunos, até seus determinantes histórico-sociais e suas influências nos conteúdos apresentados (LAJOLO, 1996; MEGID NETO; FRACALANZA, 2003; NÚÑEZ et al., 2017; CHOPPIN, 2004; NOSELLA, 2005; GARCIA; BIZZO, 2010; MARTINS; GOUVÊA; VILANOVA, 2012; SILVA, 2012; VENERA, 2013).

Por se tratar de uma produção humana, o livro didático é intrinsicamente contraditório e condicionado historicamente, fazendo com que esteja impregnado de conflitos de interesse, sejam eles de cunho ideológico, político, econômico, cultural e/ ou social (MEGID NETO; FRACALANZA., 2003; CHOPPIN, 2004; NOSELLA, 2005; GARCIA; BIZZO, 2010; MARTINS; GOUVÊA; VILANOVA, 2012). Não obstante, ele adquiriu tamanha potência dentro da sociedade que também acabou determinando, dialeticamente, algumas políticas educacionais, os currículos escolares e, principalmente, a ação dos professores (CICILLINI, 1998; NÚÑEZ et al., 2017; VASCONCELOS; SOUTO, 2003; SILVA, 2012). Por tais razões, é importante que esse material didático adote uma postura crítica frente à sua própria finalidade e seus conteúdos e, inclusive, frente às influências em seu processo de produção, como edição, impressão, distribuição, custo etc. (LAJOLO, 1996; VENERA, 2013). Assim, incorporando um pensamento de Minayo (2010) e aplicando-o aos livros didáticos, faz-se necessário que eles fujam dos extremos, seja, por um lado, ao se afirmarem como neutros, imparciais e meramente técnicos, negando seu compromisso político-pedagógico com o trabalho de professores e o progresso do conhecimento da humanidade, seja, por outro lado, ao se enclausurarem em subjetivismos e debates políticos, afastandose da prática e do conhecimento científico sistematizado.

\section{O CONCEITO DE ECOSSISTEMA}

Ecossistema é um conceito central, um dos eixos norteadores mais utilizados nos estudos da Ecologia e Biologia, sendo ainda conteúdo obrigatório do Currículo Escolar do Estado de São Paulo (PICKETTT; CADENASSO, 2002; ODUM, 2007; SÃO PAULO, 2012; KATO; KAWASAKI; 
CARVALHO, 2020). Logo, cabem as perguntas: de onde surgiu o conceito de ecossistema?; e o que ele significa e engloba atualmente?.

Segundo Odum (2007), alusões ao conceito de ecossistema existem desde os primórdios da história escrita e permeiam muitos pensamentos filosóficos, mas foi apenas no século XIX que começaram a aparecer textos formais, de caráter científico, que se referiam ao conjunto de seres vivos e de fatores abióticos e suas inter-relações. Em 1898, o geógrafo russo Vasily V. Dokuchaev (1846-1903) utilizava o termo geobiocenose para descrever um espaço delimitado, no qual os componentes vivos e não vivos representavam uma unidade internamente contraditória e dialética, que trocavam matéria e energia entre si, constantemente, por meio de relações específicas. Contudo, somente em 1935, a palavra "ecossistema" foi utilizada, pela primeira vez, pelo ecologista inglês Arthur G. Tansley (1871-1955), mas que lhe foi sugerida pelo botânico Arthur R. Clapham (1904-1990) (WILLIS, 1997; ODUM, 2007; KATO; KAWASAKI; CARVALHO, 2020). Para Tansley (1935 apud WILLIS, 1997), os seres vivos eram extremamente importantes nas análises e, com certeza, a parte que mais atraía sua atenção. Só que não podiam ser separados dos fatores abióticos do meio em que estavam inseridos, porque tais fatores também eram imprescindíveis para um estudo ecológico mais completo, fidedigno e assertivo. Nessa direção, Tansley (1935 apud BOCKING, 1994) desenvolveu o conceito de ecossistema para abarcar a complexidade e indissociabilidade das partes vivas e não vivas do ambiente, que formavam um todo tendendo ao equilíbrio.

Depois, em 1942, o estadunidense Raymond Lindeman (1915-1942) introduziu outra abordagem para o conceito de ecossistema, a de fluxo de energia entre as partes físicas, químicas e biológicas de um ambiente determinado espacial e temporalmente, criando as ideias de cadeia e teia tróficas. Logo, o foco das pesquisas passou das interações entre as espécies para as trocas energéticas entre os níveis tróficos (WILLIS, 1997). Essa mudança de paradigma trouxe algumas consequências: redução da importância dos seres vivos e até indistinção entre as partes vivas e não vivas dos ecossistemas, posto que uma carcaça realiza trocas energéticas tanto quanto um ser vivo saudável; e a legitimação de intervenções e manipulações humanas, visando a "otimização" das trocas energéticas para benefício próprio, pois o ecossistema era visto mais como uma máquina do que como um organismo (BOCKING, 1994). Nessa direção, o conceito apropriou-se da ideia de sistema, que provinha da Física, cujas bases já estavam consideravelmente estabelecidas, conferindo um aspecto "moderno", mecânico e determinado, e trazendo "rigor científico" e respeitabilidade às pesquisas em Ecologia (KATO, 2014). Ao mesmo tempo, o termo "eco" era utilizado na academia, com frequência, e remetia ao domínio próprio da Ecologia, com caráter mais biológico e relativamente preocupado com as questões ambientais (KATO, 2014; KATO; KAWASAKI; CARVALHO, 2020).

No entanto, na contramão dessa tendência, Eugene P. Odum (1913-2002), em 1957, considerou o conceito de ecossistema como unidade básica da Ecologia, e sua principal função seria realçar e enfatizar a obrigatoriedade, interdependência e causalidade das relações contidas entre os produtores, consumidores, decompositores e os fatores abióticos do ambiente, valorizando, assim, uma visão holística e mais orgânica da Ecologia (ODUM, 2007). Além disso, é importante notar que a obra desse autor foi uma das pioneiras na popularização do conceito (KATO, 2014).

Já a partir da década de 1960, houve grande expansão das pesquisas que utilizavam o ecossistema como unidade de análise. Esse boom inicial deu-se durante a Guerra Fria, patrocinado por instituições interessadas nos efeitos da radiação nuclear nos ambientes, e prosseguiu nas décadas seguintes, com o avanço e entusiasmo em relação à tecnologia e aos computadores. Isso fez com que os modelos matemáticos fossem introduzidos e, cada vez mais, utilizados na Ecologia, nas análises e nas pesquisas relacionadas aos ecossistemas, enraizando algumas características das Ciências Exatas e dando um teor preditivo e prescritivo aos estudos (BOCKING, 1994; WILLIS, 1997).

Atualmente, há intenso diálogo entre Ecologia, Economia e Ciências Sociais, resultando na incorporação de algumas noções, como capital humano, capital social, instituições, distúrbios humanos e fluxo de dinheiro, aos modelos ecológicos, buscando melhorias na gestão de recursos, nas áreas urbanas, na elaboração de políticas públicas, dentre outras (PICKETT; CADENASSO, 2002). Segundo esses autores, o conceito de ecossistema ainda é utilizado nas áreas de comunicação, como na mídia e divulgação científica, e em outras esferas sociais, mas não há atenção ou preocupação para com sua precisão conceitual, pois, nesses meios nos quais circula, ele é mais utilizado para referir-se a um mero 
local (de preferência "natural") no planeta, como uma paisagem, um ambiente, ou também para expressar valores, como conectividade, diversidade, adaptabilidade, resiliência etc.

\section{O ENSINO DE ECOLOGIA}

A Ecologia é um importante ramo das Ciências Biológicas e está presente em nossa cultura desde o início da humanidade. Seu conjunto de conhecimentos era essencial, porque saber sobre os seres vivos e suas interações em determinado ambiente era crucial à sobrevivência do grupo humano, e, ao mesmo tempo, esses ambientes nos quais os grupos estavam assentados ajudavam a moldar, e ainda moldam, a cultura local (DIEGUES, 2001; BEGON; TOWNSED; HARPER, 2006; ODUM, 2007). Contudo, com o avanço das civilizações e tecnologias e o surgimento do capitalismo, os seres humanos passaram a agir como se fossem independentes do mundo natural, sendo que todo o desenvolvimento de nossa espécie se deu à custa da exploração dos recursos naturais, a qual se intensificou desequilibrada e drasticamente nos últimos séculos. Por isso, a compreensão da sociedade, dos seres humanos e de suas contradições tornou-se indissociável da compreensão da natureza, de suas forças de produção (fotossíntese, cadeias tróficas, decomposição de resíduos etc.), dos ecossistemas e da relação destes com o mundo social, visto que o desenvolvimento da sociedade é estruturado a partir do mundo natural (PEPPER, 1993; DIEGUES, 2001; ODUM, 2007).

Logo, cabe ao domínio da Ecologia e de seus conhecimentos historicamente acumulados e sistematizados o papel de compreender e desmistificar o mundo natural e seus componentes, a relação homem-natureza, os slogans "desenvolvimento e crescimento sustentáveis" e "natureza selvagem intocada", os discursos e as políticas ambientais falaciosas etc. (FRACALANZA, D. C., 1992; PEPPER, 1993; DIEGUES, 2001; SATO; CARVALHO, 2005; SENICIATO; CAVASSAN, 2009). E, para que tais objetivos sejam atingidos, é necessária a compreensão do conceito de ecossistema, visto que ele é um dos pilares da Ecologia (FRACALANZA, D. C., 1992; WILLIS, 1997; ODUM, 2007).

Tendo em vista esses objetivos, é igualmente necessário que os professores, incumbidos do papel de mediar o processo de apropriação dos alunos, apreendam o conceito de ecossistema adequadamente, além de sua história e filosofia, de suas contradições, possibilidades e limites, de suas relações com a sociedade etc. (CONTRERAS, 2002; SAVIANI, 2009; LIBÂNEO, 2013; CARVALHO, 2016). Tal apreensão é imprescindível, sobretudo quando as normas educacionais exigem uma educação científica contextualizada e crítica, para que o aluno possa aplicar o conhecimento adquirido, não só como um mero instrumento profissionalizante, mas para entender e problematizar o mundo, apreender e sistematizar informações e, assim, exercer sua cidadania (SÃO PAULO, 2012; BRASIL, 2020). Não obstante, essa apreensão só ocorrerá se o professor se embasar em referenciais teóricos de qualidade, os quais não se restrinjam à superficialidade da realidade, mas evidenciem as contradições inerentes à produção do conhecimento e da própria vida humana - ainda mais quando se sabe não existir neutralidade, pois não há conhecimento desinteressado, ou seja, o processo educativo é também um ato político e tem de ser pensado cuidadosamente (SAVIANI, 2012; 2013).

Desse modo, almejando-se uma educação cada vez mais contextualizada e crítica, que, nesse caso, se traduz em uma compreensão ampla e problematizada do conceito de ecossistema e da Ecologia, faz-se necessário uma análise profunda dos conteúdos presentes nos livros didáticos. Nessa direção, tevese, como questão de pesquisa, a seguinte pergunta: como o conceito de ecossistema é abordado em livros didáticos?. A partir desse questionamento, foi derivado o objetivo geral deste estudo, que é o de identificar e analisar como o conceito de ecossistema é abordado em livros didáticos de Biologia do Ensino Médio, oferecidos pelo Programa Nacional do Livro Didático (PNLD).

\section{METODOLOGIA}

Foram analisadas, na íntegra, três coleções de livros didáticos de Biologia, dentre as nove aprovadas pelo PNLD/2015 (BRASIL, 2014). As três coleções foram obtidas da seguinte maneira: com o auxílio da Diretoria de Ensino - Região de Botucatu, foi feito um levantamento com os professores da disciplina de Biologia do Ensino Médio, das escolas do município de Botucatu/SP, para a identificação dos livros didáticos mais utilizados por eles. Como resultado desse levantamento, chegou-se a uma 
relação de cinco coleções, das quais foi possível à Diretoria de Ensino disponibilizar três delas, que foram as utilizadas para a análise aqui apresentada.

Para o tratamento dos dados, isto é, para inferir e desmistificar os conteúdos referentes ao conceito de ecossistema manifestos nos textos das coleções em questão, foi utilizada a Análise de Conteúdo proposta por Bardin (2011). Iniciou-se a metodologia a partir do tratamento do corpus documental (as três coleções didáticas) com a "pré-análise", que teve por finalidade uma primeira aproximação dos textos, atentando-se para suas mensagens e para as impressões, conhecimentos, emoções e expectativas que emanavam delas. A partir dessa leitura inicial, foram criados "índices" e "indicadores", que auxiliaram no preparo do material. Para que essa tarefa fosse coerente, foi necessário delimitar uma "unidade de registro" para identificar e separar os conteúdos. Assim sendo, como unidade de registro, foi escolhida a "unidade temática", por ser ampla, versátil e de ordem psicológica, não meramente linguística (BARDIN, 2011). A unidade temática foi referente ao tema "ecossistema", respeitando sempre as "unidades de contexto" (trechos do texto que são essenciais à compreensão da unidade de registro) na hora de recriar, categorizar e contabilizar os sentidos e significados contidos em cada um dos excertos.

De posse da unidade temática e de suas frequências, prosseguiu-se para a "categorização", que se constituiu na classificação e no reagrupamento ordenado dos conteúdos. As categorias de análise foram embasadas na literatura especializada, principalmente nas de Frank B. Golley (1993), um expoente e renomado ecologista norte-americano (JORDAN, 2006), que estudou o processo de elaboração e desenvolvimento do conceito de ecossistema, classificando os sentidos atribuídos a esse conceito de acordo com os debates e consensos acadêmicos em torno dele. Desse modo, Golley (1993) chegou a definir quatro grandes perspectivas, as quais serviram como ponto de partida para este estudo, a saber: "determinística", "indeterminística", "cibernética" e "organísmica", porém fez a ressalva de que uma não exclui a outra, e, às vezes, elas podem se combinar, complementando-se. De antemão, salienta-se que, por mais que as categorias criadas por Golley (1993) interpretem de forma adequada as visões do conceito de ecossistema, nenhuma é crítica às suas próprias limitações e não há tentativas de superação de tais limites. O que o autor fez foi contar uma história sobre a Ecologia de Ecossistemas e retratar as abordagens do conceito como eram utilizadas no meio acadêmico, mas sem grande envolvimento. Todavia, ainda assim, optou-se por utilizar as categorias/perspectivas de Golley (1993), com algumas modificações e acréscimos, pelo motivo de abarcarem satisfatoriamente as abordagens do conceito de ecossistema nos livros didáticos e também pela possibilidade de se problematizar suas limitações, fazendo, assim, o debate avançar.

Dessa forma, segundo Golley (1993), a visão “determinística” de ecossistema o reduz a uma unidade determinada pela soma de suas propriedades e fatores internos. Isto é, as variáveis físico-químicas e suas interações com os organismos determinam a distribuição espaço-temporal dos seres vivos. Com esse reducionismo, um ecossistema é facilmente previsível e controlável a partir da análise de seus componentes e relações, pois a comunidade (o todo) é subordinada ao ambiente físico e suas interações (as partes). Há quem discorde dessa ideia, dizendo que os ecossistemas possuem comportamento "indeterminístico", visto que as relações intra e interespecíficas que influenciam os fatores bióticos e abióticos do ambiente podem se dar de tantas maneiras que adquirem caráter aleatório. Enquanto isso, a perspectiva "cibernética" enfoca a rede e o fluxo de informações, matéria e energia dentro dos sistemas que coexistem e interagem em um ecossistema. Esse paradigma preocupa-se em observar como os componentes bióticos e abióticos do ambiente se relacionam, se retroalimentam, e ver a direção da informação, matéria e energia dentro dessas relações, as quais buscam sempre um equilíbrio estável dentro dos sistemas. Nessa perspectiva, tanto os seres vivos quanto os fatores físico-químicos dissolvemse, tornam-se indistinguíveis, pois ambos realizam trocas de informação da mesma forma, ou seja, são apenas funções, elos do sistema (GOLLEY, 1993).

Por fim, a visão "organísmica" compreende os ecossistemas como "superorganismos", possuindo um ciclo de vida (nascimento, crescimento, senescência e morte) e uma evolução "linear", que parte do simples em direção ao complexo, buscando um equilíbrio dinâmico (clímax). O paradigma "organísmico" assume um ecossistema como uma unidade homogênea, ou seja, as diversas populações animais e vegetais são equivalentes em seus "estágios de vida", estando em consonância no nível de complexidade. Alguns cientistas ampliaram essa visão criando a Hipótese Gaia, na qual a Terra toda se 
comportaria como um organismo global. Entretanto, outros autores discordam dessa ideia, porque é incongruente a comparação de características da vegetação com o desenvolvimento dos animais, sem contar que os indivíduos, dentro de um ecossistema, possuem papéis distintos, os quais variam de acordo com o espaço e o tempo, não agindo em harmonia com o "superorganismo" (GOLLEY, 1993; KATO, 2014).

Tendo delimitado as categorias originais criadas por Golley (1993), aqui será explicitado o nosso ponto de vista e as modificações realizadas na ferramenta analítica a partir de nossas impressões. No decorrer das análises, percebeu-se que a perspectiva "cibernética" era uma das mais utilizadas pelos livros didáticos, mas, por vezes, ela se dissolvia e se misturava com as outras visões (no caso deste estudo, mais especificamente, com as perspectivas "determinística" e "organísmica"), como Golley (1993) já havia alertado. Dessa forma, optou-se por fragmentar essa "grande categoria cibernética", adaptando-a aos dados e necessidades deste estudo. Assim sendo, foram elaboradas as seguintes categorias: "cibernética stricto sensu", "cibernético-finalista" e "cibernético-holista", e abriu-se mão das categorias criadas pelo autor, com exceção da "indeterminística". Essa opção teórico-metodológica tem razão de ser, porque a maioria dos excertos carregava sobreposições de perspectivas e neles havia efetivamente uma sobreposição priorizando o sentido e, até mesmo, a terminologia, mais associada à visão cibernética do conceito de ecossistema, em detrimento das demais. Além disso, essa opção também está embasada no fato de a perspectiva "cibernética" ser uma das expoentes dentro de todos os livros, e, por isso, a preferência por deixar as demais visões sob sua sombra, e não o contrário (esse aspecto dos livros será melhor discutido posteriormente).

Nessa direção, a ideia da categoria "cibernética stricto sensu" corresponde à perspectiva "cibernética" originalmente proposta por Golley (1993), já delimitada anteriormente. A categoria "cibernético-finalista" diz respeito à sobreposição da visão "cibernética" com a "determinística", conferindo uma visão mais determinada à rede e ao fluxo de informações, energia e matéria do ecossistema, enfatizando um equilíbrio mais estático do que dinâmico e, por vezes, reduzindo o todo à soma das partes. Já a categoria "cibernético-holista" é a junção das categorias "cibernética e organísmica", que prioriza uma ideia de sistema complexo, recheado de níveis tróficos, formando uma unidade viva e dinâmica que interage com tudo o que está ao redor, e, quando uma das partes, ou o todo, "morre", tudo dentro e fora do sistema/unidade é afetado. Ou seja, a categoria "cibernético-holista" enfoca principalmente os seres vivos e suas relações entre si dentro do ecossistema, em detrimento das interações com os componentes abióticos, podendo evocar a ideia de "superorganismo".

Além dessas três novas categorias, também sentiu-se a necessidade de criar uma quarta, denominada "lugar", visto que as categorias descritas anteriormente, por estarem mais embasadas nos estudos de Golley (1993), não conseguiriam abarcar todos os excertos encontrados nos livros didáticos analisados, mesmo com a adaptação feita por nós. Assim sendo, a categoria "lugar" representa trechos que simplificam e reduzem o conceito a um mero espaço físico, um local na superfície terrestre, não levando em consideração as interações entre os seres vivos e o seu ambiente.

É oportuno dizer que, neste estudo, as categorias foram construídas tendo em vista uma quantidade ótima, respeitando sempre os critérios de "pertinência, objetividade, fidedignidade e exclusão" mútuas, recomendados por Bardin (2011). Por fim, foi realizada a "inferência" segundo a "análise temática", isto é, as categorias e unidades de registro e suas frequências foram interpretadas através de suas "direções" (sentido que os excertos carregam) e "intensidades" (grau de convicção dos excertos), na tentativa de interpretar e analisar a abordagem dada aos conteúdos pelos livros didáticos.

\section{RESULTADOS E DISCUSSÃO}

Cada coleção didática analisada é composta por três livros didáticos, um para cada ano do Ensino Médio (Quadro 1). Os livros são organizados em unidades ou módulos, que possuem capítulos sobre o tema em questão (Quadro 2). Todos os livros das coleções trabalhadas foram lidos na íntegra, mas são detalhadamente descritos aqui apenas aqueles que contêm o conteúdo referente à pesquisa, ou seja, as unidades e capítulos que abordam o conceito de ecossistema. 
Quadro 1 - Coleções didáticas analisadas

\begin{tabular}{|l|c|c|}
\hline $\begin{array}{c}\text { Coleção Biologia } \\
\text { (Vivian L. Mendonça) }\end{array}$ & $\begin{array}{c}\text { Coleção Biologia em contexto } \\
\text { (José M. Amabis) }\end{array}$ & \multicolumn{1}{c|}{$\begin{array}{c}\text { Coleção Ser Protagonista } \\
\text { (Tereza C. osorio) }\end{array}$} \\
\hline Biologia (v.1) & Do universo às células vivas (v. 1) & Ser Protagonista - Biologia (v. 1) \\
\hline Biologia (v.2) & Adaptação e continuidade da vida (v. 2) & Ser Protagonista - Biologia (v. 2) \\
\hline Biologia (v.3) & A diversidade dos seres vivos (v. 3) & Ser Protagonista - Biologia (v. 3) \\
\hline
\end{tabular}

Fonte: Elaboração própria.

Quadro 2 - Livros didáticos e unidades nos quais se encontram conteúdos de Ecologia e Ecossistema

\begin{tabular}{|c|c|c|}
\hline $\begin{array}{c}\text { Biologia (v. 1) } \\
\text { (Coleção Biologia) }\end{array}$ & $\begin{array}{c}\text { Biologia em Contexto (v. 1) } \\
\text { (Coleção Biologia em Contexto) }\end{array}$ & $\begin{array}{c}\text { Biologia (v. 3) } \\
\text { (Coleção Ser Protagonista) }\end{array}$ \\
\hline $\begin{array}{l}\text { Unidade } 1 \text { - Introdução à Biologia e pricipios de } \\
\text { Ecologia }\end{array}$ & $\begin{array}{l}\text { Abertura - A visão científica da } \\
\text { natureza }\end{array}$ & Unidade 1 - Genética \\
\hline Unidade 2 - Origem da Vida e Biologia celular & Módulo 1 - A biosfera & Unidade 2 - Evolução \\
\hline \multirow[t]{3}{*}{ Unidade 3 -Embriologia e Histologia animal } & $\begin{array}{l}\text { Módulo } 2 \text { - População, comunidade e } \\
\text { humanidade }\end{array}$ & Unidade 3 - Ecologia \\
\hline & Módulo 3 - Arquitetura das células & \\
\hline & $\begin{array}{l}\text { Módulo } 4 \text { - Metabolismo energético e } \\
\text { reprodução celular }\end{array}$ & \\
\hline
\end{tabular}

Fonte: Elaboração própria.

O primeiro volume da coleção Biologia (MENDONÇA, 2013) é composto por três unidades temáticas, subdivididas em doze capítulos. A unidade de interesse desta pesquisa é a primeira (Quadro 2), e nela há cinco capítulos, sendo eles: 1) Vida e composição química dos seres; 2) Vida e energia; 3 ) Ciclos da matéria, sucessão ecológica e desequilíbrios ambientais; 4) Biomas, ecossistemas e populações; e 5) Relações entre os seres vivos.

O primeiro volume da coleção Biologia em Contexto (AMABIS, 2013) possui uma abertura e quatro módulos, subdivididos em doze capítulos. Os dois primeiros módulos, "A biosfera" e "Populações, comunidade e humanidade", contêm os temas Ecologia e Ecossistema (Quadro 2) e abarcam oito capítulos do livro, sendo eles: 1) Como a vida surgiu?; 2) O que caracteriza a vida?; 3) O fluxo de energia na natureza; 4) Os ciclos da matéria; 5) A dinâmica das populações; 6) Relações ecológicas; 7) Sucessão ecológica e biomas; e 8) A humanidade e o ambiente.

Já o terceiro volume da coleção Ser Protagonista - Biologia (OSORIO, 2013) constitui-se de três unidades (Quadro 2), subdivididas em dezesseis capítulos. A última unidade é a que contém os capítulos que dizem respeito à Ecologia e ao Ecossistema e possui cinco capítulos, sendo eles: 12) Ecologia básica; 13) Relações ecológicas; 14) Ecossistemas; 15) Biomas; e 16) O ser humano e o ambiente.

Durante a primeira aproximação com os livros, notou-se que os temas e conteúdos de Ecologia ficavam restritos às unidades referentes a esse tema. Isto é, os conceitos dessa área, assim como sua visão sistêmica e holística, que busca a compreensão das interações das partes entre si e com o todo de um ambiente, não permeiam mais nenhuma outra unidade, capítulo ou discussão dos livros, o que acaba por contribuir para uma maior segmentação e empobrecimento do conhecimento biológico. Quando muito, em alguns subtópicos e parágrafos, há apenas citação da palavra ecossistema, mas não há um desenvolvimento do conceito ou como ele se contextualiza sob essa nova lente, que não a da Ecologia. Essa fragmentação e desarticulação dos conteúdos e temáticas já foi percebida em outros estudos, como os de Martins e Guimarães (2002) e Nascimento e Martins (2005), e na revisão bibliográfica conduzida por Marpica e Logarezzi (2010) sobre livros didáticos e educação ambiental.

Já a categorização dos trechos que remetiam à ideia de ecossistema totalizou 76 excertos, sendo 33 da coleção Ser Protagonista - Biologia (OSORIO, 2013), 26 da coleção Biologia (MENDONÇA, 2013) e 17 da coleção Biologia em Contexto (AMABIS, 2013). A perspectiva mais utilizada nos livros 
didáticos foi a cibernético-holista, com 34 excertos, enquanto que a visão indeterminística só foi utilizada em um único excerto, no terceiro volume da coleção Ser Protagonista - Biologia (OSORIO, 2013). O número de excertos em cada categoria está no Quadro 3, abaixo.

Quadro 3 - Categorização dos excertos

\begin{tabular}{|l|c|c|c|c|c|}
\hline \multirow{2}{*}{ COLEÇÃO } & \multicolumn{5}{|c|}{ CATEGORIA } \\
\cline { 2 - 6 } & $\begin{array}{c}\text { Cibernética } \\
\text { Stricto sensu }\end{array}$ & $\begin{array}{c}\text { Cibernético } \\
\text { finalista }\end{array}$ & $\begin{array}{c}\text { Cibernético- } \\
\text { holista }\end{array}$ & Lugar & Indeterminístisca \\
\hline Ser Protagonista & 6 & 12 & 10 & 4 & 1 \\
\hline Biologia & 5 & 4 & 13 & 4 & 0 \\
\hline Biologia em contexto & 0 & 4 & 11 & 2 & 0 \\
\hline Total & 11 & 20 & 34 & 10 & 1 \\
\hline
\end{tabular}

Fonte: Elaboração própria.

Nos capítulos, tópicos e trechos que tratam de como são feitos a pesquisa e o estudo em Ecologia e em ecossistemas, ou seja, como os cientistas analisam os ecossistemas e quais variáveis levam em consideração, as abordagens dadas são majoritariamente a "cibernética stricto sensu" e a "cibernéticofinalista", pois elas dão a entender que os ecossistemas são conceitos operacionais, passíveis de análise, quantificação, particularização etc. Os seguintes excertos ilustram a perspectiva "cibernética stricto sensu":

$1^{\circ}$. Muitos cientistas não consideram que uma cidade seja um 'ecossistema urbano', pois, como vimos, um ecossistema apresenta fluxo controlado de energia e reciclagem de matéria. É de outros ambientes, de fora da cidade, que os moradores obtêm seu alimento e energia [...]. (MENDONÇA, 2013, p. 82).

$2^{\circ}$. Vimos que a energia flui ao longo dos ecossistemas. A matéria, ao contrário, é reciclada, ou seja, é constantemente reaproveitada. (OSORIO, 2013, v. 3, p. 205).

O primeiro excerto foi categorizado na perspectiva "cibernética stricto sensu", porque enfatiza o papel do fluxo de matéria e energia dentro dos níveis tróficos que constituem um ecossistema, compreendendo as interações como um fluxo de informações pelas partes do sistema. Além disso, no trecho, percebe-se a distinção entre mundo humano e mundo natural, já que é mostrada a opinião de cientistas que não consideram uma cidade como um "ecossistema urbano", porque ela obtém alimento e energia de outros ambientes. O segundo excerto foi igualmente categorizado como "cibernético stricto sensu", porque enfoca o fluxo de energia e o ciclo da matéria dentro do ecossistema, sem dar grandes atenções se esse fluxo e ciclo perpassam seres vivos ou componentes abióticos.

Enquanto isso, os seguintes excertos exemplificam a categoria "cibernético-finalista":

$3^{\circ}$. O movimento de matéria e energia dentro de um ecossistema implica que os produtores sirvam de alimento para um herbívoro (consumidor primário), e este, por sua vez, sirva de alimento para um carnívoro (consumidor secundário). [...] Essa relação entre os organismos de um ecossistema é a chamada cadeia alimentar, ou cadeia trófica. (OSORIO, 2013, v. 3, p. 203, grifos da autora).

$4^{\circ}$. O padrão de distribuição de uma população em um ecossistema fornece informações sobre as interações entre os indivíduos que a compõem e sobre as características ambientais. (OSORIO, 2013, v. 3, p. 231).

$5^{\circ}$. No ambiente terrestre os ecossistemas sofrem influência principalmente de fatores climáticos, como temperatura do ar e quantidade de chuva (pluviosidade), o que determina as grandes formações vegetais e as comunidades animais adaptadas a essas condições. (MENDONÇA, 2013, v. 1, p. 99).

O terceiro trecho foi categorizado como "cibernético-finalista", pois novamente aborda o fluxo de matéria e energia, mas, dessa vez, há uma diferença: as interações dão-se de uma forma 
determinada e linear, obedecendo a uma escala ascendente dentro da cadeia alimentar, na qual os níveis inferiores têm de servir aos níveis superiores. Esse excerto passa a impressão de que há um propósito por trás dessas relações, o qual atua estabelecendo regras para o funcionamento ordenado do ecossistema. O quarto excerto encaixa-se ainda nessa perspectiva, porque remete à previsibilidade de características de um ecossistema a partir de dados conhecidos; no caso, o padrão de distribuição da população pode ser utilizado para determinar as interações dos indivíduos e as características ambientais, visto que o todo é a soma das interações/informações das partes, não algo qualitativamente diferente. Já o quinto excerto parte do raciocínio inverso: se, antes, a partir do todo determinavam-se as partes, agora, a partir das partes (fatores climáticos), determina-se o todo (formações vegetais e comunidades animais).

Já nos capítulos, tópicos e trechos que tratam do aspecto evolutivo dos ecossistemas e das comunidades, da inserção dos seres humanos na natureza, assim como dos problemas ambientais advindos dessa relação homem-natureza, a abordagem dada é predominantemente a "cibernéticoholista". Ela é adotada porque induz o leitor a sentir-se integrado com e responsável pelo bem-estar do ecossistema, transmitindo a ideia de que a natureza é uma entidade que precisa ser cuidada. Os quatro excertos abaixo enquadram-se na visão "cibernético-holista" de ecossistema, porque frisam a necessidade de equilíbrio da vida no planeta Terra, como se os ecossistemas não estivessem "saudáveis" por conta das atividades humanas, as quais não estão em harmonia com o todo, ou o "superorganismo". Os trechos também buscam aproximar os seres humanos da natureza, recorrendo às emoções do leitor, dizendo que somos parte constituinte dessa natureza e, por isso, responsáveis pelo seu bem-estar. Em específico, o sétimo excerto faz um apelo à ética e moral de todos os seres humanos, para a conservação do "superorganismo".

$6^{\circ}$. Nós, seres humanos, fazemos parte da natureza assim como os outros organismos; no entanto, nem sempre contribuímos para seu equilíbrio. (MENDONÇA, 2013, v. 1, p. 82).

$7^{\circ}$. É importante refletir sobre a proteção e a conservação ambiental, e contribuir para a construção de uma sociedade mais equilibrada. A proteção e a restauração dos ecossistemas naturais devem ser prioridade de todos os povos da Terra. (AMABIS, 2013, v. 1, p. 153).

$8^{\circ}$. O estudo das transferências de energia tem revelado detalhes sobre a teia da vida na Terra. Quanto maior o nosso conhecimento da rede de relações entre os seres vivos e o ambiente, mais condições teremos de preservar os ecossistemas do nosso planeta, um dos grandes desafios do século XXI. (AMABIS, 2013, v. 1, p. 61).

$9^{\circ}$. O estudo afirma que o declínio dos superpredadores afeta os mais variados aspectos do ecossistema global, assim como o clima, o número de hábitats, a poluição, a fixação de carbono e até mesmo a propagação de doenças. Por muito tempo pensou-se que os grandes predadores, no topo da pirâmide trófica, pouco influenciavam as espécies dos níveis tróficos inferiores. (AMABIS, 2013, v. 1, p. 109).

Além disso, no oitavo excerto, percebe-se que o fluxo de energia já é citado logo de início, e seu estudo é importante para a compreensão da vida no planeta, pois tudo está interconectado e tudo se afeta. Ao mesmo tempo, o texto chama a atenção para a importância do conhecimento, agora, das interações entre seres vivos e não vivos, para que nós possamos preservar os ecossistemas da Terra, já que fazemos parte desse planeta. Por tais motivos, o oitavo excerto foi categorizado como "cibernéticoholista", enquanto que o nono excerto foi categorizado como tal por enfocar a quantidade de relações que um tipo de ser vivo, que ocupa um nível trófico/energético específico (um patamar na pirâmide), estabelece dentro do ecossistema. Ademais, no final desse trecho, ressalta-se que os cientistas pensavam que os níveis tróficos mais elevados não possuíam tamanha influência nos níveis mais basais, mas que, agora, percebem que tudo está interligado em uma unidade dinâmica.

Por outro lado, os excertos que reduzem o conceito de ecossistema a um sentido de mero espaço físico, geralmente, foram encontrados nos tópicos que tratavam dos ecossistemas aquáticos, os quais, via de regra, foram pouco desenvolvidos e explanados, ficando defasados se comparados aos demais conteúdos da Ecologia. Todavia, alguns trechos também foram encontrados em tópicos que abordavam a relação homem-natureza e tratavam os ecossistemas como um espaço físico "intocado", o qual deveria ser mantido em seu aspecto original, "natural", como pode ser visto abaixo: 
$10^{\circ}$. Para manter a rotina de consumo nas cidades, ecossistemas naturais são destruídos para ceder espaços à agricultura e pastagens para gado. O desmatamento [...] também está relacionado a quedas bruscas na biodiversidade do planeta. (MENDONÇA, 2013, v. 1, p. 82).

$11^{\circ}$. Os oceanos podem ser considerados o maior ecossistema da Terra, pois cerca de $70 \%$ da superfície do planeta está coberta por eles [...]. (MENDONÇA, 2013, v. 1, p. 97).

$12^{\circ}$. Um lago é um ecossistema de água doce sem correnteza, e um rio é um ecossistema de água doce em movimento. (AMABIS, 2013, v. 1, p. 147).

O décimo primeiro e o décimo segundo excertos são categorizados como "lugar", porque não utilizam o conceito de ecossistema de forma precisa, que, por definição, diz respeito às relações dinâmicas que existem e permeiam a comunidade e os fatores abióticos. Esses excertos transmitem uma visão simplificada do referido conceito, mostrando-o como sendo apenas um espaço físico, uma paisagem estática com algumas peculiaridades, mas sem interação alguma. Enquanto isso, o décimo excerto, além de simplificar tal conceito e desconsiderar seu enfoque nas interações, também se remete à ideia de que ecossistema é um lugar longínquo, intocado (afastado das cidades e dos seres humanos). Esse distanciamento usado na abordagem do conceito acaba por induzir uma falsa ideia de que o ecossistema é dissociado da realidade, desvalorizando-o como conteúdo curricular e também perante a Ecologia, ou seja, nesse caso, o excerto passa a sensação de que um ecossistema é equivalente a uma "paisagem", onde não ocorrem interações entre seres vivos e elementos físico-químicos, e, por isso, não há necessidade de se debruçar sobre ele, estudá-lo a fundo e preservá-lo.

Por fim, o único excerto que contém a perspectiva "indeterminística" foi utilizado em um item do tipo "a título de curiosidade" e diz explicitamente que os ecossistemas podem ser indeterminados devido, virtualmente, às infinitas variáveis que cada fator pode ter. Ele aparece em um quadro de uma página do livro, como se fosse outra forma de interpretar as relações dentro de um ecossistema, ou uma pequena crítica às visões dominantes, mas que não é desenvolvida em nenhuma outra parte do livro. Eis o excerto: "13․ Em seu livro Diversidade da vida, o biólogo E. O. Wilson ensina que os ecossistemas podem ser imprevisíveis, em razão das peculiaridades de cada espécie que interage ali” (OSORIO, 2013, v. 3, p. 204).

É interessante notar que, por mais que a categoria "cibernético-holista" tenha sido a mais utilizada, quando combinados, grande parte dos excertos enquadra-se nas perspectivas "cibernética stricto sensu" e "cibernético-finalista", e são justamente elas as utilizadas quando se objetiva explicar como é feito o estudo e a análise de um ecossistema. Assim, cabem inúmeras indagações, tais como: por que a ideia de sistema, importada da Física, é tão útil (ou tão comumente adotada) para o estudo de um ecossistema?; por que a perspectiva "indeterminística" foi apresentada somente uma vez, em apenas uma coleção, sendo que ela é tão importante quanto as demais?; será que essa perspectiva levantaria muitas questões que não seriam fáceis de responder, colocando o próprio conteúdo do livro didático em dúvida?. Essas questões despertaram o pensamento, a princípio, de que transmitir a noção de que os ecossistemas são unidades mensuráveis e previsíveis é mais fácil, prático e objetivo, principalmente no espaço limitado de um livro didático. Ao mesmo tempo, e tomando-se como amparo as discussões de Martins e Guimarães (2002) e Bonotto e Semprebone (2010), essas visões (perspectivas "cibernética stricto sensu" e "cibernéticofinalista") trazem a dicotomia homem-natureza, de caráter antropocêntrico, que acaba por justificar o domínio dos seres humanos sobre o mundo natural, já que estamos dissociados deste e que conseguimos manipulá-lo com nosso conhecimento e tecnologia. Em outras palavras, as perspectivas "cibernética stricto sensu" e "cibernético-finalista" reforçam a ideia de que os seres humanos são seres superiores e, por conseguinte, proprietários da natureza. Isso, em essência, contradiz a própria definição de ecossistema, que, por excelência, engloba todos os seres vivos e interconecta suas relações, sem exceção (BEGON; TOWNSEND; HARPER, 2006; ODUM, 2007). Ao mesmo tempo, essas perspectivas limitam a profundidade e complexidade do conceito de ecossistema, ao apresentá-lo como um construto facilmente desmembrável em fatores que possuem uma simples relação de causa e efeito.

Igualmente, saltou aos olhos a dominância da perspectiva "cibernético-holista" durante a abordagem dos problemas ambientais causados pela ação antrópica. Quando se inicia uma tentativa de problematização da atividade humana (principalmente a econômica), os livros didáticos ainda se utilizam de um teor "cibernético", que confere domínio perante a natureza, mas, igualmente, assumem um discurso romantizado, que convoca todos os seres humanos, de todas as nações, a encontrarem soluções. Esse discurso idealizado homogeneíza os seres humanos, igualando suas diferenças e diluindo suas 
responsabilidades para com a problemática ambiental (PEPPER, 1993; DIEGUES, 2001; CHARLOT; SILVA, 2005; SAUVÉ, 2005). Segundo esses autores, isso significa que as classes exploradas e oprimidas, que praticamente são as vítimas do sistema de produção que exaure o meio ambiente, são quase que, exclusivamente, culpabilizadas pela crise ambiental, já que são a maioria. Consequentemente, as classes dominantes e opressoras (e o sistema de produção em si), que são a minoria, não são devidamente problematizadas, e suas responsabilidades são encobertas pelo discurso da igualdade. Logo, os livros didáticos contribuem para a reprodução das relações de produção e dominação (NOSELLA, 2005; SILVA, 2012), seja de forma intencional ou não. O excerto abaixo ilustra essa problemática:

Entretanto, para poder desfrutar de uma longa vida na Terra, a humanidade precisa encontrar formas equilibradas de convívio com a natureza e de exploração dos recursos naturais. [...] É importante refletir sobre a proteção e a conservação ambiental, e contribuir para a construção de uma sociedade mais equilibrada. A proteção e a restauração dos ecossistemas naturais devem ser prioridade de todos os povos da Terra. [...] Nesse contexto, a Ecologia torna-se imprescindível, uma vez que, para desenvolver estratégias globais de utilização dos recursos naturais, é fundamental conhecer a composição e o funcionamento dos ecossistemas. Cuidar do planeta é, hoje, uma responsabilidade de todos os cidadãos do mundo. (AMABIS, 2013, v. 1, p. 153, grifos nossos).

Nessa direção, percebe-se que os produtores de livros didáticos tendem a reproduzir as perspectivas dominantes do conceito de ecossistema de forma acrítica, sem historização, assumindo-as e retransmitindo-as como verdades únicas e incontestáveis. Isso acaba minando o debate e as aulas sobre o tema e suas implicações, privando os leitores (tanto alunos quanto professores) de uma visão mais ampla e profunda da realidade. Isso pode ocorrer de forma intencional ou não, como já mencionado, mas também ocorre porque os livros didáticos são condicionados pelas diretrizes educacionais e programas e políticas públicas de fomento, como o currículo nacional e o próprio PNLD, por exemplo (MARTINS; GOUVÊA; VILANOVA, 2012; SILVA, 2012).

Finalmente, outra característica que cabe ressaltar é a quantidade de excertos categorizados como "lugar". Por mais que não seja alta, espanta-se que ela ocorra, visto que é um empobrecimento do conceito de ecossistema e, até mesmo, uma definição errada, já que desconsidera as interações que ocorrem, ainda mais quando utilizada para ecossistemas aquáticos, que são ricos em relações, diversidade, e igualmente poluídos e negligenciados.

\section{CONSIDERAÇÕES FINAIS}

Após a análise dos conteúdos que dizem respeito ao conceito de ecossistema, é possível dizer que nenhuma das coleções didáticas trabalhadas neste estudo contribuiu, de forma expressiva, para uma visão ampla e holística de ecossistema, tanto dentro da própria Ecologia quanto em outras áreas da Biologia, colaborando, assim, para uma compartimentalização do saber. Além disso, não há historização a respeito da construção do conceito de ecossistema, não havendo textos sobre o contexto e as influências que existiram em torno de sua elaboração. A única perspectiva histórica que existe é a menção de Arthur G. Tansley, que oculta todo um esforço de comunidades científicas mundiais e contextos históricopolítico-sociais. Dessa forma, os conhecimentos de Ecologia e, por conseguinte, o conceito de ecossistema permanecem monolíticos e mistificados, elaborados por cientistas (homens brancos) excepcionais, no alto de suas torres de marfim, distantes da realidade dos professores e alunos, como bem colocou Gil-Pérez et al. (2001). De acordo com esses autores, acrescentando-se as reflexões de Cachapuz et al. (2005) e transpondo-as para o tema desta pesquisa, esse distanciamento proporcionado pelos livros didáticos contribui para uma limitação do ensino de Biologia, que é privado de suas raízes históricas e, por isso mesmo, humanas, bem como mistifica a produção do conhecimento e do fazer científico, que se torna inalcançável por parte dos alunos, já que fica restrita aos "excepcionais".

Contudo, tem-se a ciência de que, por mais que os livros didáticos possam se apresentar como elementos limitadores do ensino-aprendizagem, existem outras dimensões que também exercem influência dentro da sala de aula e que podem minimizar essas limitações. Uma delas, aliás de grande importância, é a própria práxis docente (MARPICA; LOGAREZZI, 2010), ou seja, o compromisso técnico e político do professor (SAVIANI, 2013) ao elaborar suas aulas, e as formas que escolhe para 
transmitir os conteúdos pode suprimir as limitações dos livros didáticos e de outros materiais de apoio que porventura possa utilizar. No entanto, o livro didático não pode se furtar de seu compromisso de fornecer conteúdos bem desenvolvidos, com profundidade e amplitude, para que o professor possa nele se amparar e nortear seu trabalho. Ainda mais quando se sabe que esse é um dos materiais mais utilizados para a elaboração de aulas (FRACALANZA, H., 1992; HÖFLING, 2000; VASCONCELOS; SOUTO, 2003; BITTENCOURT, 2004; CASSIANO, 2007), e a precarização e proletarização das condições de trabalho dos professores podem dificultar, cada vez mais, sua ação (CONTRERAS, 2002).

Assim, faz-se necessária uma produção mais crítica do livro didático, que, para o caso desta pesquisa, também se traduz em uma abordagem do conceito de ecossistema que o dimensione em toda sua história e complexidade. Não é necessário jogar fora o que já se produziu, pois todas as abordagens captam, de certa forma, algumas facetas do conceito. Transmitir as perspectivas aqui trabalhadas pode continuar sendo um caminho válido para o ensino-aprendizagem em Ecologia, desde que o material evidencie as limitações, os conflitos e as potencialidades de cada uma delas, retirando seu misticismo e, com isso, aproximando-as de uma visão mais concreta da realidade. Em outras palavras, o que se sugere neste trabalho é que a melhoria da qualidade do livro didático pode ocorrer pela incorporação e superação do que já existe, com acréscimo (ou explicitação) de seu caráter humano, histórico, conflitante e contraditório. Faz-se, aqui, apenas exceção da perspectiva "lugar", pois ela não apreende o conceito de ecossistema em nenhum nível de profundidade de análise e, por isso, deveria ser evitada sempre que possível.

\section{REFERÊNCIAS}

AMABIS, J. M. Biologia em contexto. 1. ed. São Paulo: Moderna, 2013.

BARDIN, L. Análise de conteúdo. Lisboa: Edições 70, 2011.

BEGON, M; TOWNSEND, C. R.; HARPER, J. L. Ecology: from individuals to ecosystems. 4. ed. Malden: Blackwell Publishing, 2006.

BITTENCOURT, C. M. F. Em foco: história, produção e memória do livro didático. Educaşão e Pesquisa, v. 30, n. 3, p. 471-473, set./dez. 2004.

BOCKING, S. Visions of Nature and Society: A History of the Ecosystem Concept. Alternatives, v. 20, n. 3, p. 12-18, jul./ago. 1994.

BONOTTO, D. M. B.; SEMPREBONE, A. Educação ambiental e educação em valores em livros didáticos de Ciências Naturais. Ciência \& Educação, Bauru, v. 16, n. 1, p. 131-148, 2010.

BRASIL. Ministério da Educação. Secretaria de Educação Básica. Fundo Nacional de Desenvolvimento da Educação. Guia de livros didáticos: PNLD 2015: biologia: ensino médio. Brasília: MEC, 2014. 80p.

BRASIL. Ministério da Educação. Base Nacional Comum Curricular. Brasília: MEC, 2017. 595 p.

Disponível em: 
http://basenacionalcomum.mec.gov.br/images/BNCC_EI_EF_110518_versaofinal_site.pdf. Acesso em: 27 jun. 2020.

CACHAPUZ, A.; GIL-PÉREZ, D.; CARVALHO, A. M. P. de; PRAIA, J.; VILCHES, A. (Org.). A necessária renovação no ensino de ciências. São Paulo: Cortez, 2005.

CARVALHO, A. M. P. de. Formação continuada de professores: uma releitura das áreas de conteúdo. 2. ed. São Paulo: Cengage Learning, 2016.

CASSIANO, C. C. de F. O mercado do livro didático no Brasil: da criação do Programa Nacional do Livro Didático (PNLD) à entrada do capital internacional espanhol (1985-2007). 2007. 252 f. Teste

(Doutorado em Educação) - Pontifícia Universidade Católica de São Paulo, São Paulo, 2007.

CHARLOT, B.; SILVA, V. A. da. Relação da natureza com a educação ambiental. In: SATO, M.;

CARVALHO, I. C. M (Org.). Educação ambiental. Porto Alegre: Artmed, 2005. p. 67-78.

CHOPPIN, A. História dos livros e das edições didáticas: sobre o estado da arte. Educação e Pesquisa, v. 30, n. 3, p. 549-566, set./dez. 2004.

CICILLINI, G. A. Ensino de Biologia: o livro didático e a prática pedagógica dos professores do Ensino Médio. Ensino em Re-vista, v. 6, n. 1, p. 29-37, jun. 1998.

CONTRERAS, J. A autonomia de professores. São Paulo: Cortez, 2002.

DIEGUES, A. C. S. O mito da natureza intocada. 3. ed. São Paulo: Hucitec, 2001.

FRACALANZA, D. C. Crise ambiental e ensino de ecologia: o conflito na relação homem - mundo natural. 1992. 318 f. Tese (Doutorado em Educação) - Universidade Estadual de Campinas, Campinas, 1992.

FRACALANZA, H. O que sabemos sobre os livros didáticos para o ensino de ciências no Brasil. 1992. $304 \mathrm{f}$. Tese (Doutorado em Educação) - Universidade Estadual de Campinas, Campinas, 1992.

GARCIA, P. S.; BIZZO, N. A pesquisa em livros didáticos de ciências e as inovações no ensino. Educação em Foco, v. 13, n. 15 p. 13-35, jul. 2010.

GIL-PÉREZ, D.; MONTORO, I. F.; ALÍS, J. C.; CACHAPUZ, A.; PRAIA, J. Para uma imagem não deformada do trabalho científico. Ciência \& Educaşão, v. 7, n. 2, p. 125-153, 2001.

GOLLEY, F. B. A history of the ecosystem concept in ecology: more than the sum of parts. London: Yale University Press, 1993. 
HÖFLING, E. de M. Notas para discussão quanto à implementação de programas de governo: Em foco o Programa Nacional do Livro Didático. Educação \& Sociedade, v. 21, n. 70, p. 159-170, abr. 2000.

JORDAN, C. F. The life and career of Frank B. Golley (1930-2006) and his role in awakening north american ecology to the international realm. Tropical Ecology, v. 47, p. 155-157, 2006.

KATO, D. S. O conceito de "ecossistema" na produção acadêmica brasileira em educação ambiental: construção de significados e sentidos. 2014. 233 f. Tese (Doutorado em Educação) - Universidade Estadual Paulista “Júlio de Mesquita Filho", Araraquara, 2014.

KATO, D. S.; KAWASAKI, C. S.; CARVALHO, L. M. Os significados do conceito de ecossistema para a compreensão do discurso ambiental: análises de livros didáticos do ensino superior de Ecologia. In: ENCONTRO NACIONAL DE PESQUISA EM EDUCAÇÃO EM CIÊNCIAS, 10., 2015, Águas de Lindóia. Ata [...]. Águas de Lindóia/SP: X EMPEC, 2015. Área: Linguagens, discurso e educação em ciências. Linha temática: Linguagens, discurso e Educação de ciências: abordagens discursivas, argumentação, interações discursivas, leitura e escrita no ensino de ciências. Disponível em: . Acesso em: 30 jun. 2020.

LAJOLO, M. Livro didático: um (quase) manual de usuário. Em Aberto, v. 16, n. 69, jan./mar. 1996.

LIBÂNEO, J. C. Didática. 2. ed. São Paulo: Cortez, 2013.

MARPICA, N. S.; LOGAREZZI, A. J. M. Um panorama das pesquisas sobre livro didático e educação ambiental. Ciência \& Educação, v. 16, n. 1, p. 115-130, 2010.

MARTINS, E. de F.; GUIMARÃES, G. M. A. As concepções de natureza nos livros didáticos de ciências. Ensaio Pesquisa em Educação em Ciências, v. 4, n. 2, p. 1-14, dez. 2002.

MARTINS, I.; GOUVÊA, G.; VILANOVA, R. (Org.). O livro didático de Ciências: contextos de exigência, critérios de seleção, práticas de leitura e uso em sala de aula. 1. ed. Rio de Janeiro: FAPERJ, 2012.

MEGID NETO, J.; FRACALANZA, H. O livro didático de ciências: problemas e soluções. Ciência \& Educaşão, v. 9, n. 2, p. 147-157, 2003.

MENDONÇA, V. L. Biologia. 2. ed. São Paulo: AJS, 2013.

MINAYO, M. C. S. O desafio do conhecimento: pesquisa qualitativa em saúde. 12. ed. São Paulo: Hucitec, 2010. 
NASCIMENTO, T. G.; MARTINS, I. O texto de genética no livro didático de ciências: uma análise retórica crítica. Investigações em Ensino de Ciências, v. 10, n. 2, p. 255-278, 2005.

NOSELLA, M. de L. C. D. As belas mentiras: a ideologia subjacente aos textos didáticos. 13. ed. São Paulo: Centauro, 2005.

NÚÑEZ, I. B.; RAMALHO, B. L.; SILVA, I. K. P. da; CAMPOS, A. P. N. A seleção dos livros didáticos: um saber necessário ao professor. O caso do ensino de Ciências. Revista Iberoamericana de Educacion, p. 1-12, 2003. Disponível em: http://www.rieoei.org/deloslectores/_427Beltran.pdf. Acesso em: 16 set. 2017.

ODUM, E. P. Fundamentos de ecologia. 5. ed. São Paulo: Pioneira Thomson, 2007.

OSORIO, T. C. Ser Protagonista: biologia. 2. ed. São Paulo: Edições SM, 2013.

PEPPER, D. Eco-socialism: from deep ecology to social justice. Londres: Routledge, 1993.

PICKETT, S. T. A; CADENASSO, M. L. The Ecosystem as a Multidimensional Concept: Meaning, Model and Metaphor. Ecosystems, v. 5, 2002.

SÃO PAULO. Estado. Secretaria da Educação. Currículo do Estado de São Paulo: Ciências da Natureza e suas Tecnologias. 1. ed. atual. 2012.

SATO, M.; CARVAlHO, I. C. M. (Org.). Educaşão ambiental. Porto Alegre: Artmed, 2005.

SAUVÉ, L. Educação ambiental: possibilidades e limitações. Educação e Pesquisa, v. 31, n. 2, p. 317-322, maio/ago. 2005.

SAVIANI, D. Formação de professores: aspectos históricos e teóricos do problema no contexto brasileiro. Revista Brasileira de Educação, v. 14, n. 40, jan./abr. 2009.

SAVIANI, D. Escola e democracia. 42. ed. Campinas: Autores Associados, 2012.

SAVIANI, D. Pedagogia histórico-crítica: primeiras aproximações. 11. ed. rev. Campinas: Autores Associados, 2013.

SENICIATO, T.; CAVASSAN, O. O ensino de ecologia e a experiência estética no ambiente natural: considerações preliminares. Ciência \& Educação, v. 15, n. 2, p. 393-412, 2009. 
SILVA, M. A. A Fetichização do Livro Didático no Brasil. Educação \& Realidade, v. 37, n. 3, p. 803-821, set. 2012.

TANSLEY, A. G. The use and abuse of vegetational concepts and terms. Ecology, v. 16, n. 3, p. 284$307,1935$.

TANSLEY, A. G. The use and abuse of vegetational concepts and terms. Ecology, v. 16, n. 3, p. 284307, 1935 apud BOCKING, S. Visions of Nature and Society: A History of the Ecosystem Concept. Alternatives, v. 20, n. 3, p. 12-18, jul./ago. 1994.

TANSLEY, A. G. The use and abuse of vegetational concepts and terms. Ecology, v. 16, n. 3, p. 284307, 1935 apud WILLIS, A. J. The Ecosystem: An Evolving Concept Viewed Historically. Functional Ecology, v. 11, n. 2, p. 268-271, abr. 1997.

VASCONCELOS, S. D.; SOUTO, E. O livro didático de ciências no ensino fundamental - proposta de critérios para análise do conteúdo zoológico. Ciência \& Educação, v. 9, n. 1, p. 93-104, 2003.

VENERA, R. A. S. O funcionamento de tipologias discursivas em livros didáticos de história. Educação em Revista, v. 29, n. 1, p. 121-150, mar. 2013.

WILLIS, A. J. The Ecosystem: An Evolving Concept Viewed Historically. Functional Ecology, v. 11, n. 2, p. 268-271, abr. 1997.

Submetido: $23 / 04 / 2018$

Aprovado: $10 / 04 / 2020$

Contato:

Renato Eugênio da Silva Diniz

Rua Dr. Domingos Minicucci Filho, 289 - Vila Sônia

Botucatu|SP|Brasil

CEP 18.607-030 